have a most deleterious effect on the health of children. I think, therefore, it is not unreasonable that the school doctor should consider the whole environment of the school and not be concerned with developmental assessment isolated from some of the factors which could affect overall development.

I think it is not usual for the examination of teachers to be part of the duties of a school medical officer. Most authorities tend to have separate sessions at which medical officers may be asked to undertake such examinations and, again, I do not feel that they can be completely divorced from concern for the health and welfare of the child. There can be few more harmful influences on a child's career than to be subjected to a physically or mentally disturbed teacher. Again I speak from personal experience and I think it is sound that doctors who work in the school health service should have some opportunity of considering the suitability of teachers, on medical grounds, to work with children.

Finally, it has long been considered a duty of all doctors in the preventive field to practise health education, and why this should be considered wrong for school doctors is completely beyond my comprehension. I would have hoped that both $\mathrm{Dr}$. Bamford and Professor Davis practised health education diligently during their work as paediatricians.

I would not wish my criticism of one section of the paper to imply any other than general agreement with the views of the authors and respect for their excellent paper. -I am, etc.,

ANTONY J. Essex-CATER Monmouthshire County Health Department, Newport, Mon

\section{Occupational Medicine?}

SIR,-Your leading article (3 February, p. 250) expresses criticisms of the Robens Report that will find a wide measure of agreement among doctors working in industry. However, the statement that "occupational physicians and occupational health nurses spend up to $90 \%$ of their time in aiding the resettlement and rehabilitation of people who have been or are becoming sick or disabled and need a change in their work" does appear to exaggerate the extent of this particular function.

It is true that the doctor or nurse within a works has the advantage over colleagues outside industry of knowledge of the demands of various types of work, and experience of the effects of these upon persons in varying states of health. But this advantage is of value in other aspects of occupational medicine. When new materials are introduced the first indication of toxic reactions may be the occurrence of minor sickness seen at the works clinic, and such an observation may lead to immediate investigation and elimination of a potential risk before serious harm occurs. A medical service based outside the works must wait for official reports of one sort or another before any problem is known to exist. The introduction of new materials is unceasing, so that detection, investigation, and elimination of new hazards is an increasingly important function of the works medical officer.

The Robens Committee implied that the works doctor wastes medical resources by duplicating functions of the N.H.S. Yet the works clinic acts as an observation post for what is going on not only in the works, but also at all levels of management, where the causes of stress may be detected sooner and morc effectively by the man on the spot than by observers based outside the works. It is an oversimplification to regard rehabilitation and resettlement as the major part of his work. Nevertheless you are right in saying that we have failed signally to be sufficiently explicit and convincing abou what occupational medicine is. $-I$ am, etc.

\section{W. K. S. MOORE}

Occupational Health Service,

The Boots Company Ltd.

Nottingham

SIR,-In your recent leading article "Occupa-
tional Medicine?" (3 February, p. 250) (the question mark is significant) you suggest that a concept of occupational medicine wider than that shown by the Robens Committee is needed.

The practice of occupational medicine is the application of medical art and science to people in their working situation, to help them keep and improve health. This concept is sufficiently wide to embrace all those matters with which, as you point out, many occupational physicians and nurses have for long been concerned. Interest in occupational medicine is quickening, not only in the medical schools but also among the general public, and if those who know its importance exert their influence, as they may be expected to do, occupational medicine will soon be accepted as part of medicine as a whole and its isolation from the mainstream of medical life ended.-I am, etc.,

University of Bristol

T. G. F. HUdSON

\section{Children's Wheelchairs}

SIR,-In reply to Dr. R. H. Taylor's letter (20 January, p. 173) concerning children's wheelchairs, the equipment is traditional not only because the engineers who design it do not have correct training but also because those who prescribe it do not give the correct details. It is not for the engineers to prescribe.

There are few anthropometric data on normal children under the age of five and none on handicapped children. The clinical involvement of engineers is, as Dr. Taylor states, non-existent. Equally, there is no move in the medical, nursing, and paramedical professions to include modern technology in their trainings-that is, anatomy in relation to biomechanics and anthropometrics, physiology in relation to work, and environmental physiology and psychology in relation to skill and occupational psychology. These are the components of ergonomics. Poor ergonomics can exist only when ergonomic principles are applied.

Ergonomics is a technical subject which is concerned with the careful collection of data about individuals as physiological and psychological beings in an endeavour to make the physical working environment compatible with them. It is used by industry in car design and in the armed Forces, but rarely in the National Health Service. It is time that it became a subject of serious postgraduate study for relevant sections of the health service.

If the design of equipment and aids, not only for children, but for handicapped and impaired people in general, is to be improved, then those who prescribe them must be correctly trained. Do not let us condemn the engineers and designers who are doing their best to provide equipment when they are not given the correct specification because of lack of training of the prescriber. Let the blame be fairly taken.

I am a nurse and an ergonomist but was unable to find any post in the Health Service where I could use my ergonomic training. Fortunately for me, industry is not so backward.-I am, etc.,

Pauline Bretten

London E.18

\section{Sponsored Hospitality}

SIR,-Mr. K. Norcross in his letter (3 February, p. 294) concerning drug firm hospitality raises what appears to him to be a disquieting point.

As a junior doctor I have attended many such meetings in a number of hospitals in this region and I can see how distasteful such hospitality can appear to be if it is misunderstood by those not attending the meeting. This hospitality certainly provides the likes of me with some light relief, but I feel that the lure of some food or drink only increases the enjoyment of the meeting and the numbers attending. I do not feel any more favourably disposed to the drug firm's products. Indeed, the atmosphere merely favours a more lively, critical, and often amusing discussion.

I think it is a shame that these meetings should be viewed with such suspicion and even banned in some hospitals. We should surely not admit that we could be bribed into using one product rather than another, and the banning of such meetings does just that.-I am, etc.

STEPHEN BRENNAN

Royal Hospital,

Sheffeld

\section{Insulin Syringes}

SIR,-There has long been concern over mistakes which are made, particularlv by patients but also by nursing and medical staff, in the dosage of insulin. This is due in large measure to the various strengths per $\mathrm{ml}$ available on the market. Some effort to minimize these mistakes has been made by attempting to insist that only the B.S. 1619 insulin syringe should be used. Even this allows of mistake because of the use of terms like "single" and "double" strength. This can be confusing with soluble insulin, which is still supplied in strengths of 20,40 , and 80 units $/ \mathrm{ml}$.

In the U.S.A. it is proposed that only a single strength insulin of 100 units $/ \mathrm{ml}$ shall be on the market. I do not think this is suitable, as the greater the "strength" of the insulin, the greater the difficulty of measuring small doses or small dose changes. 
It obviously means the adoption of a new syringe if we take up the same system.

I should like to make the following suggestions: (1) Scrap all $20 \mathrm{unit} / \mathrm{ml}$ insulin preparations. (2) Retain 40 and $80 \mathrm{unit} / \mathrm{ml}$ strengths. (3) Supply new syringes clearly stamped " 40 " or " 80 " in heavy black type and calibrated accordingly. A slip could be inserted with each syringe and in each packet of insulin reading "use only 40 syringe with 40 bottle; "use only 80 syringe with 80 bottle."

These measures would, I am sure, rule out most errors.-I am, etc.,

E. R. SPEARING

Mayday Hospital,

Thornton Heath, Surrey

\section{Fees for Cremation Certificates}

SIR,-A fee of up to $£ 4$ and even more is now being charged for the completion of both part $B$ and part $C$ of cremation forms. Some doctors feel that this fee is an unprofessional and distasteful extortion from their patients' families at a time of stress and grief.

In general practice the position is often different, but in the majority of deaths occurring in hospitals it can be argued that the doctors do not have to make any special journeys or examinations in order to fill in the forms and do not themselves incur expenses. The pursuit of cremation fees has resulted in embarrassing procedures. In at least one hospital for some time one doctor exercised the prerogative of signing the second part of all the cremation forms and collecting the fees, perhaps at a cut-price rate. A popular practice in hospitals is for the money from cremation fees to be paid into a mess fund so that no junior doctor benefits financially from working in a ward where deaths are frequent. There has also been a tendency for some hospital authorities to charge a smaller amount in the cases of hospital contract funerals, although there are more frequent cases in which family poverty might justify a reduced fee.

Opinion within the medical profession is probably divided on this subject and it is possible that more doctors condemn these fees than might at first be suspected. They accept the money, feeling perhaps that they themselves have to make to others many payments of which they disapprove.-I am, etc.,

\section{A. SPENCER}

Meanwood Park Hospital, Leeds

\section{Side Effects of Lithium Carbonate}

SIR,-I have under my care a very intelligent physicist, aged 50, who has suffered from recurrent bouts of depression. At his request and with my agreement he was given lithium carbonate $250 \mathrm{mg}$ thrice daily. He complained of certain side effects and his own account of these is as follows:

"A few days after starting to take lithium carbonate I noticed a strange and unpleasant taste associated with certain foods. The first to be affected were butter and celery; both had a strong flavour quite unl ke anything else $I$ have experienced. The 'new' flavour seemed superimposed on the original taste, and was the same for both these foods. Cooked celery also had a strong associated smell, which I found most unpleasant; other vegetables tasted and smelt perfectly normal. I stopped taking butter and changed to margarine. After about two weeks, cream and mild cheese developed the same taste, and then margarine. Other food (for example, milk, eggs, and apples) remained normal, while some vegetables (such as onions) tasted slightly unpleasant. Food generally seemed less appetizing. Even a trace of butter (for example, in cakes) rendered them very unpalatable. After stopping taking the lithium, taste returned to normal within two days, and food again became appetizing."

I have not seen descriptions of these particular symptoms before and should be interested to know whether they have previously been noted.-I am, etc.,

\section{J. Elwes Duffield}

Littlemore Hospital,

Oxford

\section{Nutritional Value of School Meals}

SIR,-Contrary to the implication in the letter from Susan M. and Dr. M. C. Bateson (27 January, p. 234) in our survey (23 December, p. 697) the food brought from home and bought elsewhere compared unfavourably with the school meal.

As we reported, the survey method employed in our study was the use of a questionnaire. All children were asked to state in detail exactly what they had selected and how much they had eaten during the lunch break. The senior schoolchildren proved able to give an acceptable record of their consumption of the school meal and food obtained elsewhere. Representative samples of all the foods the children consumed were collected and weighed. This information, together with all data collected on consumption, was converted into terms of nutrient content.

The direct weighing method of food offered and food wasted from all sources is the only one which gives an absolutely precise measure of food intake. However, within the framework of our study and the fact that there is good evidence ${ }^{1}$ to show that the method employed compares well with precise weighing methods, we believe this study reflects the nutritional value of the midday meals of senior schoolchildren.-We are, etc.,

D. P. RICHARDSON

Queen Elizabeth College,

M. LAWSON

1 Samuelson, G., Acta Paediatrica Scandinavica, 1971. Supplement 214.

\section{Anomalies in Tendon Reflexes}

SIR,-I have recently been investigating tendon reflexes, using needle electrode myography and a reflex hammer with a triggering mechanism for the oscilloscope.

The maximum delay on the tendon hammer between contact and start of the oscilloscope trace is less than one microsecond as measured on a monitoring oscilloscope.

I have noted that I have been recording action potentials, as elicited as a reflex, with the characteristics of polyphasicity and temporal dispersion, as one finds in com- pression neuropathies, in addition to finding absolute delays on latency. I would be interested to hear from other workers who may have observed this phenomena, and I would be grateful if they will contact me.

\section{B. WHITTAKER}

Royal Herbert Hospital,

Woolwich,
London S.E.18

\section{The Pill and Venereal Disease}

SIR,-Some of us who have spent years in controlling infectious diseases feel that public discussion has been focused too much on the prevention of unwanted pregnancies and not nearly enough on the alarming increase in venereal disease. This leads one to the simple question of what form of preventative should be made available to applicants under any extension of the present method of issue.

In my opinion, the contraceptive pill should be prescribed virtually only for married women, who are less likely to be subjected to the dangers of promiscuity than are sexually enthusiastic single people. For the unmarried it would seem that the rational procedure would be to educate them in the careful use of the sheath, which alone keeps the sexual organs from actual contact. I think this might be safer for the male than copper intrauterine devices.-I am, etc.,

GUY BOUSFIELD

Broadbridge Heath,

\section{Infantile Mumps}

SIR,-During the current epidemic of mumps I have seen a baby of 11 months with the typical picture of mumps complicated by bilateral epididymo-orchitis.

Is this a record? - I am, etc.,

\section{B. S. MILNER}

Edenbridge, Kent

\section{Chondromalacia Patellae}

SIR,-In your leading article (15 April 1972, p. 123) on chondromalacia patellae reference was made to our work on the bony changes in this condition, 1 with the comment that further clinical information would be of interest.

All the patients investigated were referred by orthopaedic surgeons or rheumatologists with a diagnosis of chondromalacia patellae. Only patients fulfilling stipulated criteria, ${ }^{2}$ which included those outlined in your article, were accepted. The patients subjected to patellectomy had a history ranging from eight to 27 months, with a mean of 15 months. Those investigated with $87 \mathrm{~m}-\mathrm{Sr}$ bone scans had histories ranging from six to 20 months with a mean of 12 months.

Since the preliminary report we have investigated a further 24 patients with bone scans and six patellae after patellectomy. All have had changes identical with those already described. Cartilaginous changes were found in only 12 of the total of 17 patellae examined, which is similar to the incidence of such changes found in non-symptomatic knees at necropsy, ${ }^{3}$ while the changes de- 